\title{
Study on Dynamic Construction Mechanics of Small-Distance Tunnel in Soft and Weak Rocks
}

\author{
Hengbin $\mathrm{Wu}$ (Corresponding author) \\ Department of Civil Engineering, Chongqing Three Gorge University \\ 780 Erduan Shalong Road, Wanzhou District, Chongqing 404000, China \\ E-mail: hbw8456@163.com \\ Yunxiang $\mathrm{He}$ \\ Department of Civil Engineering, Chongqing Three Gorge University \\ 780 Erduan Shalong Road, Wanzhou District, Chongqing 404000, China \\ Guoliang Song \\ Liaocheng Jianyu Construction Engineering Co.,Ltd \\ Liaocheng 252000, China
}

\begin{abstract}
Based on the construction theory of New Austria Method(NAM), relyed on a tunnel project of small distance in soft and weak rocks, this paper builds the numerical model and simulates 3D finite element method elastoplastic of the construction process by the construction method of double-sidewalls. The displacement changes of some points around the tunnel are analysised with the tunnel's excavation. The safety of the tunnel structure and stability of surrounding rock are estimated by analyzing the surface subsidence, forces undertaken by the supporting structures and plastic zone. The results show that the method of construction mentioned above is reasonable, the influence of the later tunnel excavation on the surface subsidence and tunnel deformations of the earlier tunnel excavation is relatively obvious.
\end{abstract}

Keywords: Soft and weak rocks, Small distance tunnel, Dynamic construction mechanics, Numerical simulation

\section{Introduction}

The excavation and supporting process of tunnel is a complicated mechanical process, the differences of construction process, excavation sequence and supporting time greatly influence on the mechanics effects of engineering structure systematic(SHE et al., 2006). Because of the complexity of the condition of surrounding rock, the ordinary analogy of projects is not enough in the complex lining in soft and weak rocks especially in the tunnel engineering with small distance, so it's necessary to conduct the mechanical simulating and analyzing in different surrounding rock characters according to the different forcing stages in each load case during construction processes.

In the aspect of the research on the tunnel lining in soft and weak rocks, SUN et al. (1994) builded the three dimension model considering the time-space effect of tunnel excavating surface. CHENG et al. (1997) analyzed the mechanical mechanism and carrying capacity of complex lining for tunnels with FLAC, and got some useful conclusions. JIN et al. (1996) conducted three dimension FEM (finite element method) numerical simulation to the excavation processes of circle tunnel using the nonlinear viscoelastic theory. Karakus(2007)elaborated three dimension excavating effect caused by plane strain analyses. Because the time-space effect could not be fully reflected, many researchers conducted three dimension FEM elastoplastic and visco-elastoplastic analyses to tunnel excavation(AN, 1994, XIAO, 2000 \& ZHU et al., 1996).In the aspect of the research in the tunnel of small distance, LIU et al. (2000) carried out the tests on Zhaobaoshan tunnel, which is the first super small distance tunnel in China. WAN et al. (2000) made specifically the concept of small distance tunnel. JIN et al. (2004) discussed the adaptability of the construction methods through the numerical simulating. YAN et al. (2006) analyzed the mechanical characteristic and deformation rules of the supports in different construction methods. LIU et al. (2006) introduced the design scheme of highway tunnel of small distance with 8 lanes. Most of studies mentioned above were aimed separately at construction characters of the tunnel in soft and weak rocks 
and the comparison and selection of the construction schemes of small distance tunnel. The discussion combining the two aspects is less made, so it's necessary to study the dynamic construction mechinics characteristic of small distance tunnel in soft and weak rocks.

\section{Engineering General Situation}

\subsection{Engineering Geology}

The geological survey shows that the bottom, the tunnel mostly get through, is the Jurassic upper Shaximiao, and the underlying bedrock is the interbedded of mudstone and sandstone. The strike direction of the strata intersect the tunnel axis to $85^{\circ}$, the strata dip angle is about $9^{\circ}$, the combination between the layers of rock is general, and the level of rock is grade V. The groundwater is poor, and the main form of the water in tunnel is damp or dripping. The saturated uniaxial compressive strength of mudstone $\mathrm{Rc}=4.59 \mathrm{Mpa}$, Integrity factor $\mathrm{Kv}=0.65$, $\mathrm{K} 1=0.2, \mathrm{~K} 2=0.3, \mathrm{~K} 3=0,[\mathrm{BQ}]=219$. The saturated uniaxial compressive strength of Sandstone $\mathrm{Rc}=25.49 \mathrm{Mpa}$, integrity factor $\mathrm{Kv}=0.64, \mathrm{~K} 1=0.5, \mathrm{~K} 2=0.2, \mathrm{~K} 3=0,[\mathrm{BQ}]=319$. The surface of geological structure is very developed, the rock body is extremely fragmented, and the block strength is not strong. So it belongs to the typical category of the soft and weak rocks.

\subsection{Engineering Construction Method}

The double side-walls construction method is guided under the supporting role with advanced small pipe, in order to reduce the influence of tunnel construction on the highway operations, ensure the safety of tunnel construction. The outside radius of advanced small pipe is $\Phi 42 \mathrm{~mm}$, the length is $3.5 \mathrm{~m}$ and the circumferential spacing is $40 \mathrm{~cm}$. In the construction process, the excavation length is controlled strictly, the primary support is constructed every $4 \mathrm{~m}$, and the $30 \mathrm{~cm}$ thick closed loop of steel concrete is molded between the secondly lining and primary support. The bolts are the forms of hollow grouting and quincunx layout, the diameter and length are setted as $25 \mathrm{~mm}$ and $4.5 \mathrm{~m}$, the vertical and circumferential spacing are located $200 \mathrm{~cm}$ and $80 \mathrm{~cm}$ apart. The primary support and secondly lining are forms of the $28 \mathrm{~cm}$ thick C20 shotcrete and $60 \mathrm{~cm}$ thick $\mathrm{C} 25$ model reinforced concrete.

\section{Numerical Model}

The tunnel length in simulating model is selected as $20 \mathrm{~m}$, and the model has 21850 elements, in which bolts have 3850 elements(Fig.1). The tunnel surrounding rock is considered to be elastoplastic material. Because the mechanics characteristic of the support structure is better than the surrounding rock, so it could be regarded as elastic material. The effect of steel arch shelf in shotcrete and advanced small pipe could be simulated using equivalent method. Tab.1 is the basic mechanics parameter of the material. In order to ensure the veracity of calculation, the model dimension can be set as : left and right are all $50 \mathrm{~m}$, vertical to earth surface, down is $50 \mathrm{~m}$.

\section{Results Analysis}

\subsection{Surface Subsidence Analysis}

The surface subsidence should be strictly controlled, in order to ensure the safety of highway operations in the tunnel construction. From Fig.2, the graph of the surface subsidence after completion of the tunnel excavation, it can be seen that the surface subsidence is approximate symmetrical distribution on the two-lane tunnel, showing W shape. the surface subsidence in the top of the earlier tunnel vault is largest, the value is $5.31 \mathrm{~mm}$, which is due to the construction disturbance caused by the later tunnel after completion of the earlier tunnel excavation. This is consistent with the information and data rules of on-site monitoring. The surface subsidence in the top of the later tunnel vault is $5.31 \mathrm{~mm}$, the surface subsidence near the central axis line are smaller than the top of the two tunnel vaults, the value is only $2.87 \mathrm{~mm}$. Generally speaking, the surface subsidence can guarantee normal construction under the safety operation of highway. The conclusion, which could also be seen from Fig.2, is that the impact of the tunnel excavation on surface subsidence tends to be stable in the range of the distances of 3.5 times the diameter to the central axis, which also indicates the selection range of this simulation model is within the error.

\subsection{Tunnel Deformation Analysis}

As can be seen from Fig.3, the vertical subsidence of the later tunnel vault is $7.20 \mathrm{~mm}$, and the largest value of the vertical subsidence, which appears in the earlier tunnel vault because of the construction effect of the later tunnel, is $7.33 \mathrm{~mm}$. The value of crown settlement is slightly small compared with the on-site monitoring value of the tunnels with general shallow-depth and large-span. It can be assumed that, the advanced small pipe has played effectively a role of reinforcing rock. The invert heaving value is relatively large, the earlier tunnel and later tunnel are $9.87 \mathrm{~mm}, 9.85 \mathrm{~mm}$. The analysis indicates that the vertical deformation of the tunnel surrounding 
rock meets the construction requirement, the initial parameters set of the tunnel structures are reasonable.

\subsection{Analysis of Forces Undertaken by Supports}

As can be seen from Fig.4, the largest value which appears in the arch foot is 7.31Mpa. The on-site monitoring in the arch foot should be strengthened in the construction process. From Fig.5, it can be found that, the axial force of bolts is larger in the position of the vault and hance, the largest value is $42.56 \mathrm{kN}$, which meets the requirement of the tensile strength. The most distribution of the bolts axial force is the form of "convex belly", which is consistent with the distribution pattern of the bolt axial force in soft and weak rocks. A small amount of bolts in arch foot position are compression state, which maybe due to the stiffness of the primary support is too large, resulting in less deformation of arch foot and the phenomenon of invert heaving. As can be seen from Fig.6, the stress law of the secondly lining is similar with primary support. The side-wall stress is larger than the others, the largest value is $0.2 \mathrm{Mpa}$, which meets the requirement criterion in China.

\subsection{Plastic Zone Analysis}

From Fig.7, it can be seen that, the plastic zone is mainly distributed in the position of the vault, arch and arch foot, which is probably due to the side-walls undertaken excessive forces caused by double-sidewalls construction method. The supports of advanced small pipe, primary support and secondly lining can prevent effectively the further expansion of the plastic zone, the depth of plastic zone does not exceed the half of the tunnel width, which is within the allowable range. Therefore the development of plastic zone of the tunnel does not affect significantly the stability of the tunnel, and the tunnel is still in stable condition.

\section{Conclusions}

The distribution of the tunnel surface subsidence is on the central axis basis, showing $\mathrm{W}$ shape, and the settlement mainly concentrated in the range of the distance of 3.5 times the diameter to the central axis. The support of advanced small pipe can reinforce the surrounding rock, and prevent effectively the expansion of the plastic zone between the two tunnels. From the deformation results of the surrounding rock, it can seen that, the influence of the later tunnel excavation on the surface subsidence and tunnel deformations of the earlier tunnel excavation is larger than the earlier tunnel impacts on the later tunnel. From the results analysis mentioned above of the surface subsidence, vertical displacement of the tunnel surrounding, undertaken forces of the supports and the plastic zone, the construction schemes of double- sidewalls is reasonable.

\section{References}

SHE Jian, \& HE Chuan. (2006). 3D elastoplastic numerical simulation of surrounding rock displacement in soft surrounding rock sectionduring construction process. Chinese Journal of Rock Mechanics and Engineering, 3, 623-629.

SUN Jun, \& ZHU He-hua. (1994). Mechanical simulation and analysis of behavior of soft and weak rocks in the construction of a tunnel opening. Rock and Soil Mechanics, 4, 20-33.

Cheng Hua, \& Sun Jun. (1997). Numerical analysis of large nonlinear deformation mechanism for complex tunnel lining in incompentent countryrock. Rock and Soil Mechanics, 4, 327-336.

JIN Feng-nian, \& QIAN Qi-hu. (1996). Simulation of three-dimensional tunnel excavations. Rock and Soil Mechanics, 3, 193-200.

M.Karakus. (2007). Appraising the methods accounting for 3D tunneling effects in 2D plane strain FE analysis. Tunnelling and Underground Space Technology, 22, 47-56.

AN Guan-feng. (2001). 3D-FEM for the effect of soft-soil creep on tunnel. Chinese Journal of Civel Engineering, 5, 87-91.

XIAO Ming. (2000). Three-dimensional numerical model of construction process for underground opening. Chinese Journal of Geotechnical Engineering, 4, 421-425.

ZHU Wei-shen, \& HE Man-chao. (1996). Surrounding rock stability under complicated condition and rock dynamic construction mechanics. Beijing: Science Press.

LIU Yan-qing, HAN Shi-hang, LU Ru-sui, \& MA Rong-tian. (2000). Experimental study on mechanical characteristics of twin tunnels with small spacing. Rock and Soil Mechanics, 5, 590-594.

WAN Ming-fu. (2000). Discussion of the tunnel surrounding rock spacing and study on the tunnel with small distance, highway, 7, 55-58.

JIN Xiao-guang, LIU Wei, QIN Feng, \& WANG Jian-hua. (2004). Excavation method analysis of little distance 
tunnel in freeway. Jouranal of Eailway Engineering Society, 2, 63-68.

YAN Qi-xiang, HE Chuan, \& YAO Yong. (2006). Study on Construction characteristic and dynamic behavior of soft rock tunnel. Chinese Journal of Rock Mechanics and Engineering, 3, 572-577.

LIU Hong-zhou, \& CHEN Jia. (2006). Structure design and analysis of shallow-embedding long-span neighbourhood highway tunnel, highway, 12, 217-222.

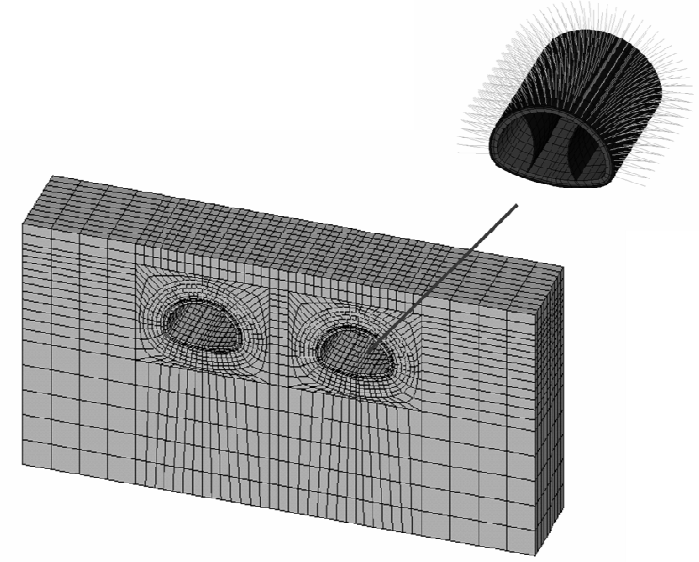

Figure 1. The Finite Element Analysis Model

Table 1. Basic mechanical parameters of surrounding rock and tunnel structures

\begin{tabular}{|c|c|c|c|c|c|}
\hline & $\mathrm{E} / \mathrm{MPa}$ & $\gamma / \mathrm{KN} / \mathrm{m}^{3}$ & $\mathrm{c} / \mathrm{MPa}$ & $\varphi / \circ$ & $\mu$ \\
\hline Surrounding Rock & 410 & 21 & 0.104 & 29 & 0.38 \\
\hline Reinforced Rock & 460 & 21 & 0.129 & 32 & 0.35 \\
\hline Primary Support & 28000 & 23 & - & - & - \\
\hline Sencondly Lining & 31000 & 25 & - & - & - \\
\hline
\end{tabular}

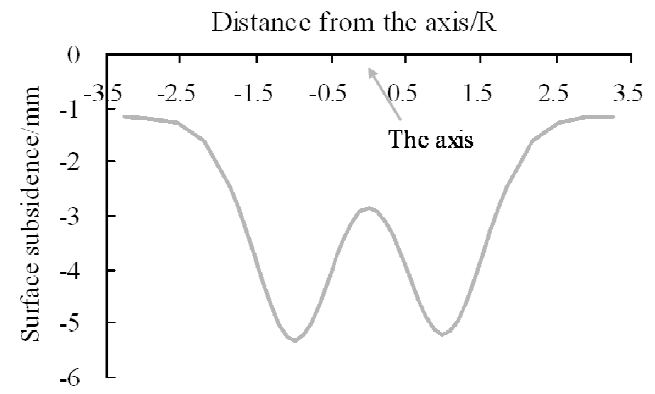

Figure 2. The Graph of Surface Subsidence 


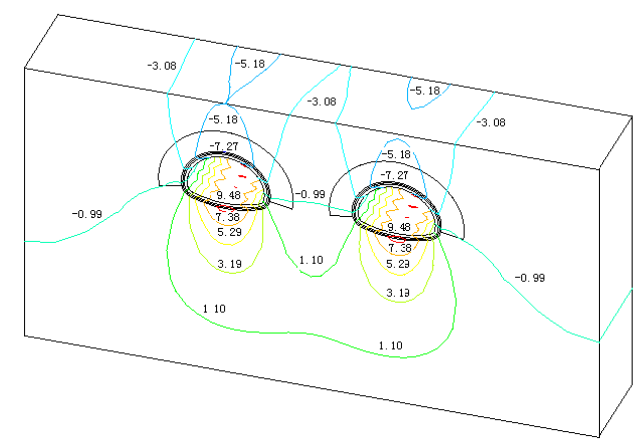

Figure 3. The Vertical Displacement of the Surrounding Rock(mm)
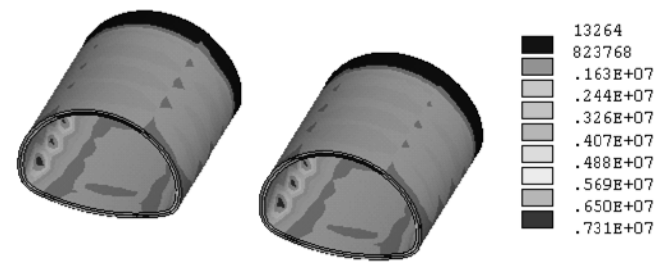

Figure 4. The Equivalent Stress of the Primary Support(pa)

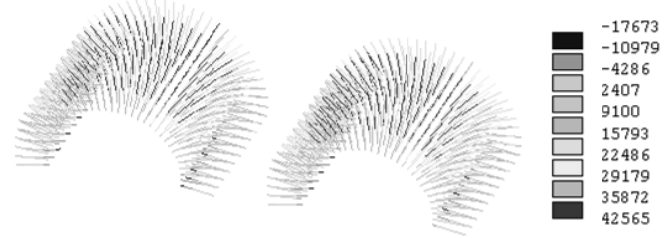

Figure 5. The Axial Force of the Bolts(N)
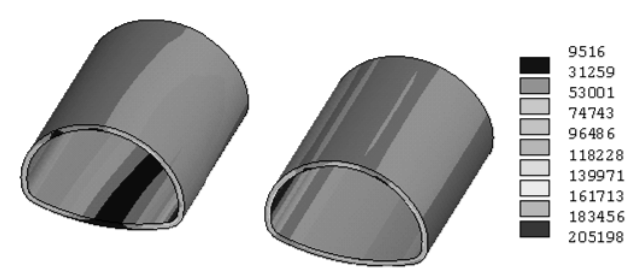

Figure 6. The Equivalent Stress of the Secondly Lining(pa)

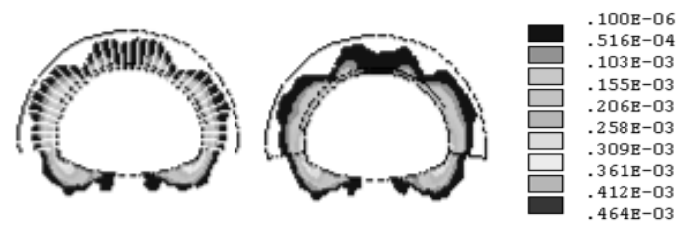

Figure 7.The Plastic Zone of the Surrounding Rock 